\title{
Educação financeira nos anos iniciais do ensino fundamental: revisão sistemática em
}

\section{banco de dados}

\author{
Financial education in the early years of elementary school: systematic database review
}

Educación financiera en los primeros años de la escuela primaria: revisión sistemática de la base de datos

\author{
Clévia Israel Faria França \\ ORCID: https://orcid.org/ 0000-0002-8948-7964 \\ Universidade Pitágoras Unopar, Brasil \\ E-mail: clevia.franca@educadores.net.br \\ Helenara Regina Sampaio Figueiredo \\ ORCID: https://orcid.org/0000-0001-7974-0818 \\ Universidade Pitágoras Unopar, Brasil \\ E-mail: helenara@kroton.com.br
}

\begin{abstract}
Resumo
Em uma sociedade na qual o consumismo e o endividamento dos cidadãos podem indicar a falta de Educação Financeira, constata-se que essa realidade atinge o conhecimento financeiro da infância até a vida adulta. Este artigo apresenta como objetivo geral realizar uma análise bibliográfica a respeito do tema Educação Financeira nos anos iniciais do Ensino Fundamental, de 2016 a 2021. A metodologia empregada no presente artigo ampara-se na revisão sistemática de dissertações e teses, por meio dos descritores: Educação Financeira, Anos Iniciais do Ensino fundamental, PIBID (Programa Institucional de Bolsa de Iniciação à Docência), Formação de Professores e TAD (Teoria Antropológica do Didático), os quais foram incluídos no campo de busca, como do banco de periódicos da Coordenação de Aperfeiçoamento de Pessoal de Nível Superior, na Biblioteca Digital Brasileira de Teses e Dissertações, e no Google Acadêmico. Após a seleção das pesquisas publicadas, realizou-se uma minuciosa análise de conteúdo, considerando: aspectos metodológicos, problemática discutida e implicações para a prática pedagógica, bem como o suporte para educação financeira. Os resultados obtidos culminaram em 412 trabalhos; após selecionar os anos iniciais do Ensino Fundamental, formação inicial e formação continuada, oito pesquisas foram reduzidas - 6 dissertações e 2 teses - que foram tomadas para leitura e análise do conteúdo. Conclui-se que as práticas pedagógicas e a formação docente contribuem para a aquisição de conhecimentos teóricos e práticos sobre Educação Financeira, apesar de ser observado que estudos focalizados na atuação docente voltados à Educação Financeira nos anos iniciais do Ensino Fundamental mostram-se escassos na prática escolar.
\end{abstract}

Palavras-chave: Educação financeira; Formação de professores; Teoria antropológica do didático; Ensino fundamental.

\begin{abstract}
In a society in which consumerism and the indebtedness of citizens may indicate a lack of Financial Education, it is found that this reality affects financial knowledge from childhood to adulthood. This article has as it's general objective to carry out a bibliographical analysis on the topic of Financial Education in the early years of Elementary School, from 2016 to 2021 . The methodology used in this article is based on the systematic review of dissertations and theses, using the descriptors: Financial Education, Early Years of Elementary School, PIBID (Institutional Program for Teaching Initiation Scholarship), Teacher Training and TAD ( Anthropological Theory of Didactics), which were included in the search field, such as from the database of the Coordination for the Improvement of Higher Education Personnel, the Brazilian Digital Library of Theses and Dissertations, and Google Scholar. After selecting the published research, a thorough content analysis was carried out, considering: methodological aspects, discussed issues and implications for pedagogical practice, as well as support for financial education. The results obtained culminated in 412 works; after selecting the initial years of elementary school, initial education and continuing education, eight researches were reduced -6 dissertations and 2 theses - which were taken for reading and content analysis. It is concluded that pedagogical practices and teacher training contribute to the acquisition of theoretical and practical knowledge about Financial Education, although it is observed that studies focused on teaching activities aimed at Financial Education in the early years of Elementary School are scarce in practice school.
\end{abstract}

Keywords: Financial education; Professional development; Anthropological theory of didactics; Elementary school. 


\begin{abstract}
Resumen
En una sociedad en que el consumismo y endeudamiento de los ciudadanos pueden indicar una falta de Educación Financiera, es claro que esta realidad afecta el conocimiento financiero desde la niñez hasta la edad adulta. Este artículo tiene como objetivo general realizar un análisis bibliográfico sobre el tema de la Educación Financiera en los primeros años de la Educación Primaria, de 2016 a 2021. La metodología utilizada se sustenta en la revisión sistemática de disertaciones y tesis, con los siguientes descriptores: Educación Financiera, Primeros Años de Educación Primaria, PIBID (Programa de Becas de Iniciación Docente Institucional), Formación Docente y TAD (Teoría Antropológica de la Didáctica), los cuales fueron incluidos en él: banco de revistas de la Coordinación de Perfeccionamiento del Personal de Educación Superior, Biblioteca Digital Brasileña de Tesis y Disertaciones, y en Google Académico. Se Realizo un análisis de contenido, considerando: aspectos metodológicos, temas discutidos e implicaciones para la práctica pedagógica, así como el apoyo a la educación financiera. Los resultados obtenidos culminaron en 412 trabajos; luego de seleccionar los años iniciales de primaria, educación inicial y educación continua, se redujeron ocho investigaciones - 6 disertaciones y 2 tesis- que se tomaron para lectura y análisis de contenido. Se concluye que las prácticas pedagógicas y la formación docente contribuyen a la adquisición de conocimientos teóricos y prácticos sobre Educación Financiera, aunque se observa que los estudios enfocados a actividades docentes orientadas a la Educación Financiera en los primeros años de la Escuela Primaria son escasos en la práctica escolar.
\end{abstract}

Palabras clave: Educación financiera; Formación de profesores; Teoría antropológica de la didáctica; Enseñanza fundamental.

\title{
1. Introdução
}

De acordo com a Pesquisa de Endividamento e Inadimplência do Consumidor (PEIC), realizada pela Confederação Nacional do Comércio de Bens, Serviços e Turismo - CNC, o número de famílias endividadas no Brasil alcançou 67,5\%, em abril de 2021. Esse resultado revela que as constantes e intensas mudanças na economia brasileira têm desafiado as pessoas a gerenciar suas finanças.

Enquanto a preocupação com o orçamento familiar aumenta, em meio à crise econômica acentuada pela pandemia da COVID-19, identifica-se a necessidade de o ensino voltar-se à Educação Financeira como estratégia, que, desde cedo, orientaria as crianças/jovens a refletirem sobre o dinheiro e o que de fato a ele está ligado (valores econômicos e políticos).

Os atuais questionamentos frente à problemática do ensino da Educação Financeira, veiculada nas mídias sociais, como indicado pela Infomoney (2021) evidenciam que o acesso das crianças ao conhecimento financeiro demandam grandes desafios, dentre os quais a insegurança dos professores em sala de aula ao introduzirem tal tema, o que torna evidente a necessidade da formação dos professores em Educação Financeira, por meio de atividades e metodologias pedagógicas direcionadas ao consumo consciente, controle do próprio dinheiro, elaboração de uma reserva de emergência, entre tantos outros tópicos.

Cabe, aqui, citar a Teoria Antropológica do Didático (TAD), proposta por Yves Chevallard - aprimorada por muitos pesquisadores de vários países - que se refere a uma teoria desenvolvida no quadro da Didática da Matemática francesa que aprova a análise de circunstâncias de ensino e aprendizagem da matemática escolar.

O tema supracitado mostra-se relevante, pois parte da formação de professores, uma vez que o professor deve compreender a disciplina que ministra, com o intuito de buscar a interdisciplinaridade, promovendo a ampliação do conhecimento por parte dos alunos (Chevallard, 2007).

Não de modo exclusivo à formação dos professores, como para o desenvolvimento contínuo de material didático, nota-se a necessidade do ensino da Matemática Financeira a partir de documentos que possam regulamentar a matéria na Educação Básica em território brasileiro.

Portanto, optou-se, neste artigo, por uma análise de produção científica da área de Educação Financeira. Posto isto, delimitou-se à investigação do estudo a abordagem que incluísse as áreas da Educação Financeira, articuladas com a formação inicial e continuada de professores dos anos iniciais do Ensino Fundamental. 
Para alcançar os tópicos levantados pelas discussões teóricas, o presente artigo encontra-se estruturado da seguinte forma: no referencial teórico, apresenta-se a revisão sistemática que tem como questão principal as propostas dos pesquisadores brasileiros em relação às práticas em prol de uma Educação Financeira nos anos iniciais do Ensino Fundamental. Na sequência, expõe-se os procedimentos metodológicos; seguindo para análise dos resultados encontrados (levantamento bibliográfico) e, por último, as considerações finais.

\section{Referencial Teórico}

Em princípio, Nóvoa (1992) identifica a necessidade de envolvimento das seguintes questões centrais: a) conhecimentos mobilizados no que diz respeito à formação do professor, práticas e experiências; b) construção da profissão docente de acordo com às transformações no que se refere às especificidades dos saberes; e c) escola e/ou local instituído para o trabalho e a formação docente.

Para a compreensão dos conceitos matemáticos, mostra-se importante tanto a reflexão quanto a participação ativa do aluno na construção do conhecimento, conforme indica Freire (1996), visto que a realização do processo ocorre por meio da interação de palavras, reflexões e ações.

De acordo com Tardif (2002), a pluralidade de saberes forma uma espécie de reservatório no qual o professor procura modelos simplificados de realidade e motivos para validar seus julgamentos a partir de sua ação.

D’Ambrósio (2002) identifica que a matemática busca criatividade, sendo importante instrumento para a tomada de decisão, uma vez que o comportamento ético resulta do conhecimento dos resultados e das decisões que tomamos.

Chevallard (2007) identifica que a escola atual se volta para a resolução de dar respostas prontas aos alunos. Portanto, para o autor, a nova organização escolar deveria fazer as perguntas e procurar meios de respondê-las a partir de uma questão inicial. Dessa forma, transformando o papel do professor o qual torna-se um orientador do estudo a partir do momento que ele elabora determinada questão inicial (denominada de nova metodologia Percurso de Ensino e Pesquisa - PEP).

Chevallard (2009) identifica o PEP como um domínio novo de pesquisa denominado didática da investigação codisciplinar, sendo esquematizado a partir da noção de sistema didático que substitui o desafio didático por uma questão Q, isto é, a qual busca uma resposta que satisfaça as restrições a priori, por meio da confrontação apropriada aos meios didáticos.

Para Tardif (2012), o professor de profissão não é apenas quem aplica conhecimentos fornecidos por outros, mas é o sujeito que consegue definir suas práticas e possuir conhecimentos, isto é, trata-se de um saber-fazer de sua própia atividade a partir da qual o orienta.

De acordo com Teixeira (2017), existe a importância da articulação dos saberes por parte do professor que irá organizar e ministrar sua aula, considerando o nível de entendimento dos alunos, sendo que o professor precisa compreender a organização da disciplina que irá lecionar, pensando na interdisciplinaridade e na maneira com que os alunos irão absorver o conteúdo aplicado.

Ainda para o autor, a formação docente é fundamental para o desenvolvimento educacional do indivíduo, porém, educar não é apenas o repasse de informação, mas, sim, de oferecer instrumentos para que o indivíduo escolha o caminho ideal aos seus valores.

Vieira (2019) assinala que quando se trata de formação inicial de cursos de licenciatura, inclusive de matemática, percebe-se críticas referentes aos currículos, métodos de ensino e distância entre práticas de formação e práticas de ensinar por parte de professores formadores, pesquisadores e egressos dos cursos de licenciatura.

Considerando que, desde o início da vida escolar, deve ser desenvolvido no aluno o pensamento matemático, cabe destacar a diferença entre Educação Financeira e Matemática Financeira no ensino. 
Bonneau (1980) discorre sobre a matemática, cuja matéria é uma linha que modela, quantifica e auxilia o entendimento de fatos econômicos os quais permeiam as operações financeiras em determinado período (financiamentos e investimentos). Assim, evidenciando as operações financeiras em que o tempo e as taxas de atualização se identificam como instrumentos de cálculos desenvolvidos pela matemática.

Conforme mencionado, a matemática financeira auxilia na compressão das operações matemáticas que cercam a vida comercial cotidiana, desde operações simples até as mais complexas (Bonneau, 1980).

Para OCDE (2009), trata-se do processo no qual tanto a sociedade quanto os indivíduos compreendem e identificam oportunidades e riscos de produtos financeiros, de forma que suas decisões influenciarão o futuro de maneira positiva a depender de suas atitudes com relação ao dinheiro.

Assim, a Estratégia Nacional de Educação Financeira Brasil-ENEF (2010) orienta que discentes e docentes educados financeiramente serão menos propensos ao descontrole envolvendo dívidas e situações adversas. E, ainda no que se refere ao ensino fundamental, salienta a necessidade de atividades e métodos em que haja a ligação entre instrução, trabalho e práticas sociais, identificando os seguintes objetivos:

(i) criação de pensamento em EF desde os primeiros anos do ensino fundamental, (ii) construção de conexões entre áreas de conhecimento (e não entre conteúdo formal), e (iii) melhoria do desempenho dos alunos em Português e Matemática, posto que essas disciplinas são consideradas críticas por todas as avaliações educacionais no Brasil (ENEF, 2010, p. 12).

O conceito de Educação Financeira é apresentado pelo Banco Central do Brasil (2012) como método por meio do qual indivíduos e sociedade buscam compreender conceitos e produtos financeiros a fim de compreender a relação risco e retorno na tomada de decisão.

Observa-se que Educação Financeira não se relaciona à quantidade de dinheiro, porém, a maneira de aproveitar o dinheiro com responsabilidade. Logo, é possível observar, por meio da defesa de D’Aquino e Maldonado (2012), que a facilidade com que uma criança é convencida ao observar a propaganda colorida pode levá-la a concluir, portanto, de que o carro/objeto é legal e precisa ser comprado imediatamente.

Assim, conforme o teórico mencionado, convencer um adulto sobre características como potência do motor, manutenção, valores das peças que o compõem, ou mesmo, a economia proporcionada pelo carro torna-se complicado e racional, portanto, o foco acaba sendo por meio do convencimento das crianças (D’Aquino e Maldonado, 2012). Dessa forma, a gestão do marketing midiático evidencia um cenário de consumismo, no qual consumidores são influenciados a efetuarem seus gastos movidos pelo imediatismo, bem como a utilizar todo o limite do cartão de crédito e cheque especial ou quando existe a liberação de crédito das mãos de grandes empresas por parte do governo.

Para Olivieri (2013), a Educação Financeira é uma forma de estar aberto ao processo constante de aprendizagem, desenvolvendo a capacidade integral do ser humano, responsável pelo uso do dinheiro para viver bem e equilibradamente.

A Base Nacional Comum Curricular - BNCC (Brasil, 2018) discute a Educação Financeira como um tema integrador para o ensino nas diversas áreas do conhecimento. Nesse sentido, a temática é contemplada em aptidões de todos os componentes curriculares, sendo de competência das escolas e sistemas de ensino, dentro de suas possibilidades, apresentá-la de maneira contextualizada. Podemos constatar essa reflexão no exemplo que segue: na disciplina de História, por exemplo, uma das competências direciona-se a compreensão dos mecanismos de transformação e manutenção das estruturas sociais, políticas, econômicas e culturais ao longo do tempo, neste sentido é possível desenvolver um estudo do dinheiro e sua função na sociedade, assim como a relação entre tempo e dinheiro, ou ainda, impostos, consumo em dados momentos históricos, incluindo estratégias atuais de marketing, entre outros (Brasil, 2018). Outro exemplo é a temática grandezas e medidas, que 
podem ser utilizadas na resolução de problemas envolvendo compra, venda e pagamento, destacando a ética do consumo consciente (Brasil, 2018).

Em resumo, nesta seção, tratou-se da área da Educação Financeira na visão de alguns teóricos e dos documentos norteadores ao ensino. Logo, constatou-se que, embora o governo tenha tornado curricular a disciplina de Educação Financeira, existe a necessidade de conteúdos sobre a temática nas escolas, mesmo que ainda na educação infantil, com o objetivo de fornecer conhecimento de como administrar o dinheiro, resultando em qualidade de vida aos futuros adultos da nação brasileira.

\section{Procedimentos Metodológicos}

No presente artigo, optou-se por realizar uma revisão sistemática da literatura que, segundo Sampaio e Mancini (2007), norteia o desenvolvimento de projetos, por essa revisão indicar a direção para novas investigações.

Keele (2007) define a revisão bibliográfica sistematizada como a aplicação de estratégias científicas que limitam o viés de seleção de artigos, e, avaliam com espírito crítico de modo a sintetizarem todos os estudos relevantes em um tópico específico.

Desse modo, foram reunidas teses e dissertações de programas de pós-graduação credenciados, tendo como fonte o banco de periódicos da Coordenação de Aperfeiçoamento de Pessoal de Nível Superior (CAPES), também, a Biblioteca Digital Brasileira de Teses e Dissertações (BDTD) e o Google Acadêmico.

Nos bancos de dados citados, a busca sistemática dos dados ocorreu entre o período de 2016 e 2021, a partir dos seguintes descritores: "Educação Financeira", "ensino e aprendizagem", "anos iniciais", "Ensino Fundamental”, "PIBID” (Programa Institucional de Bolsa de Iniciação à Docência), "formação de professores", "TAD (Teoria Antropológica do Didático)", "percurso de ensino e pesquisa" e "sequência didática". O Descritor "Educação Financeira" foi o único utilizado de forma isolada e, posteriormente, mantido fixo para combinar com os demais por meio do comando AND ${ }^{1}$.

Em relação à combinação de descritores, o que possibilitou um maior número de estudos foram os seguintes comandos: "ensino e aprendizagem" atrelados à "Educação Financeira", cujas combinações resultaram em estudos relevantes. Já os comandos "Educação Financeira" e "TAD (Teoria Antropológica do Didático)" geraram poucos estudos nos bancos de buscas

Em princípio, foram encontrados 412 trabalhos, porém, observou-se que, muitas vezes, a temática tratada não era compatível com os objetivos da pesquisa, para isso mostrou-se necessário a aplicação de critérios de inclusão, como: i) estar focado na temática de Educação Financeira; ii) estar relacionado a formação de professores; e iii) estar voltado para os anos iniciais do Ensino Fundamental.

Referentes ao critério de exclusão, elencou-se: (i) pesquisas que se referiam ao Ensino Fundamental dos anos finais, Ensino Médio, Ensino Superior, Ensino de Pós-graduação, ou ainda, Ensino da Matemática Financeira e suas propostas metodológicas, além de Formação de Professores para outras áreas do conhecimento. Por fim, após a aplicação dos critérios chegou-se ao número de 8 trabalhos sobre os quais recaiu a análise de dados.

Os trabalhos que atenderam aos critérios para esta revisão foram classificados em duas categorias (Formação Inicial de professores e Formação continuada de professores) que nortearam as análises que seguem no tópico seguinte.

\footnotetext{
${ }^{1}$ Este comando relaciona palavras ou grupos de palavras no processo de elaboração da pesquisa e serve para interligar dois descritores.
} 


\section{Resultados e Discussões}

Após a leitura e análise sistematizada a partir dos descritores de busca, os dados serão apresentados de forma a demonstrar algumas relações descritivas. Em seguida, serão evidenciadas as implicações dos estudos para as práticas pedagógicas do ensino da Educação Financeira. Contudo, adianta-se que serão discussões as quais identificam os apontamentos de cada pesquisa e dos autores da área investigada.

No Quadro 1, constam oito trabalhos/pesquisas científicas que propõem alguma proposta metodológica sobre a temática Educação Financeira, conforme segue:

Quadro 1 - Pesquisas selecionadas de acordo com o tema Educação Financeira nos anos iniciais do Ensino Fundamental.

\begin{tabular}{|c|c|c|c|}
\hline TÍTULO & AUTOR(A) & DATA & PROGRAMA \\
\hline $\begin{array}{l}\text { EDUCAÇ̃̃O FINANCEIRA EM LIVROS } \\
\text { DIDÁTICOS DE MATEMÁTICA DOS ANOS } \\
\text { INICIAIS DO ENSINO FUNDAMENTAL: } \\
\text { QUAIS AS ATIVIDADES SUGERIDAS NOS } \\
\text { LIVROS DOS ALUNOS E AS ORIENTAÇÕES } \\
\text { PRESENTES NOS MANUAIS DOS } \\
\text { PROFESSORES? }\end{array}$ & $\begin{array}{l}\text { Laís Thalita } \\
\text { Bezerra dos } \\
\text { Santos }\end{array}$ & 2017 & $\begin{array}{l}\text { Universidade Federal de } \\
\text { Pernambuco } \\
\text { (ABREVIAÇÃO) - } \\
\text { Centro de educação } \\
\text { Programa de Pós-Graduação } \\
\text { em Educação Matemática e } \\
\text { Tecnológica }\end{array}$ \\
\hline $\begin{array}{l}\text { EDUCAÇÃO FINANCEIRA NO ENSINO } \\
\text { FUNDAMENTAL: CONHECIMENTOS } \\
\text { IDENTIFICADOS EM UM GRUPO DE } \\
\text { PROFESSORES DO QUINTO ANO }\end{array}$ & $\begin{array}{l}\text { Daniela Flores } \\
\text { Teixeira }\end{array}$ & 2017 & $\begin{array}{l}\text { Universidade Católica de São } \\
\text { Paulo (PUC/SP) - Programa } \\
\text { de mestrado em Educação } \\
\text { Matemática da Pontifícia }\end{array}$ \\
\hline $\begin{array}{l}\text { EDUCAÇÃO FINANCEIRA NOS ANOS } \\
\text { INICIAIS DO ENSINO FUNDAMENTAL: } \\
\text { COMO TEM OCORRIDO NA SALA DE } \\
\text { AULA? }\end{array}$ & $\begin{array}{l}\text { Anaelize dos } \\
\text { Anjos Oliveira }\end{array}$ & 2017 & $\begin{array}{l}\text { Universidade Federal de } \\
\text { Pernambuco (XXX) Centro } \\
\text { de Educação Programa de } \\
\text { Pós-Graduação em Educação } \\
\text { Matemática e Tecnológica }\end{array}$ \\
\hline $\begin{array}{l}\text { ATIVIDADES DE EDUCAÇ̃̃O FINANCEIRA } \\
\text { EM LIVRO DIDÁTICO DE MATEMÁTICA: } \\
\text { COMO PROFESSORES COLOCAM EM } \\
\text { PRÁTICA? }\end{array}$ & $\begin{array}{l}\text { Arlam Dielcio } \\
\text { Pontes da Silva }\end{array}$ & 2018 & $\begin{array}{l}\text { Universidade Federal de } \\
\text { Pernambuco (XXX) - } \\
\text { Programa de Pós-Graduação } \\
\text { em Educação Matemática e } \\
\text { Tecnológica }\end{array}$ \\
\hline $\begin{array}{l}\text { EDUCAÇÃO FINANCEIRA: OLHAR SOBRE } \\
\text { A PRÁTICA DO PROFESSOR QUE ENSINA } \\
\text { MATEMÁTICA NOS ANOS INICIAIS DO } \\
\text { ENSINO FUNDAMENTAL }\end{array}$ & $\begin{array}{l}\text { Silvia Helena da } \\
\text { Silva e Souza }\end{array}$ & 2019 & $\begin{array}{l}\text { Universidade Federal do Pará } \\
(X X X) \text { - Programa de Pós- } \\
\text { Graduação em Docência em } \\
\text { Educação em Ciências e } \\
\text { Matemáticas }\end{array}$ \\
\hline $\begin{array}{l}\text { UM ESTUDO SOBRE A FORMAÇÃO E } \\
\text { ATUAÇÃO DOS PROFESSORES DE } \\
\text { MATEMÁTICA EM RELAÇÃO À } \\
\text { EDUCACCÃO FINANCEIRA NOS } \\
\text { MUNICÍPIOS DE CARANGOLA -MG, } \\
\text { DORES DO RIO PRETO - ES E ESPERA } \\
\text { FELIZ - MG }\end{array}$ & $\begin{array}{l}\text { Tiago Vanini } \\
\text { Vieira }\end{array}$ & 2019 & $\begin{array}{l}\text { Universidade Federal } \\
\text { Fluminense }(\mathrm{XXX}) \text { - Instituto } \\
\text { Noroeste Fluminense de } \\
\text { Educação Superior }\end{array}$ \\
\hline $\begin{array}{l}\text { CONSTRUÇÃO DE CONCEITOS DE } \\
\text { EDUCAÇÃO FINANCEIRA ESCOLAR NA } \\
\text { FORMAÇÃO INICIAL DE PROFESSORES } \\
\text { DOS ANOS INICIAIS NA PERSPECTIVA DA } \\
\text { EDUCAÇÃO MATEMÁTICA REALÍSTICA }\end{array}$ & $\begin{array}{l}\text { Susana } \\
\text { Machado } \\
\text { Ferreira }\end{array}$ & 2020 & $\begin{array}{l}\text { Universidade Franciscana } \\
\text { (XXX) Programa de Pós- } \\
\text { Graduação em Ensino de } \\
\text { Ciências e Matemática }\end{array}$ \\
\hline $\begin{array}{l}\text { EDUCAÇÃO FINANCEIRA NO CONTEXTO } \\
\text { DA EDUCAÇ̃̃O MATEMÁTICA: } \\
\text { POSSIBILIDADES PARA A FORMAÇÃO } \\
\text { INICIAL DO PROFESSOR }\end{array}$ & $\begin{array}{l}\text { Ana Karina } \\
\text { Cancian Baroni }\end{array}$ & 2021 & $\begin{array}{l}\text { Universidade Estadual } \\
\text { Paulista Júlio de Mesquita } \\
\text { Filho (UNESP) - Instituto de } \\
\text { Geociências e Ciências Exatas } \\
\text { do Câmpus de Rio Claro }\end{array}$ \\
\hline
\end{tabular}

Fonte: Autores. 
De acordo com os resultados exibidos no Quadro 1, constata-se que as pesquisas, ainda discretas, contemplam o tema em estudo. Neste contexto, após a leitura dos trabalhos relevantes para este artigo, notou-se que os autores utilizaram como referencial teórico documentos oficiais do Ministério da Educação, além de referências de estudos voltados ao consumo, matemática, Educação Financeira e propostas pedagógicas para a Educação Financeira implantadas ao currículo escolar.

Cabe destacar que o Programa de Pós-Graduação Stricto Sensu que apresentou elevada produtividade de trabalhos, a partir da proposta de métodos para o ensino de Educação Financeira, com foco na formação de professores foi o Programa de Pós-graduação em Educação Matemática e Tecnologia da Universidade Federal de Pernambuco que apresentou três produções, sendo duas, em 2017, e uma, no ano de 2018.

Os trabalhos que atenderam aos critérios para esta revisão foram, então, classificados em duas categorias que nortearam as análises: i) Formação Inicial de professores, e ii) Formação continuada de professores.

\subsection{Formação inicial de professores}

Segundo Vieira (2019), a formação docente é fundamental para a desenvolvimento educacional do indivíduo, porém, educar não é apenas o repasse de informação, mas, sim, é auxiliar a conscientização por parte da pessoa e da própria sociedade. Trata-se, de acordo com o autor, em oferecer instrumentos para que o indivíduo escolha o caminho ideal a seus valores, bem como para sua visão e adversidades da vida.

Vieira (2019) identifica que, quando se trata de formação inicial, a percepção é de que os cursos de licenciatura, inclusive a Matemática, são alvos de críticas com relação aos currículos, métodos de ensino e distância entre práticas de formação e práticas de ensinar, tanto por parte dos professores formadores quanto dos pesquisadores e egressos dos cursos dessa licenciatura.

A partir de uma busca por trabalhos que objetivam a investigação da Educação Financeira e a formação inicial de professores nos anos iniciais do ensino fundamental, constatou-se a ocorrência de duas teses e uma dissertação, bem como mostra o Quadro 2, a seguir:

Quadro 2 - Formação Inicial de Professores sobre a temática Educação Financeira nos anos iniciais do E.F.

\begin{tabular}{|lll|}
\hline Ano da Publicação & Autor(a) & Título da pesquisa concluída \\
\hline $\mathbf{( 2 0 1 9 )}$ & Tiago Vanini Vieira & $\begin{array}{l}\text { Um estudo sobre a atuação e a formação dos } \\
\text { professores de matemática em relação a Educação } \\
\text { Financeira }\end{array}$ \\
\hline $\mathbf{( 2 0 2 0 )}$ & Suzana Machado Ferreira & $\begin{array}{l}\text { Construção de conceitos de Educação Financeira } \\
\text { Escolar na Formação de Professores dos anos iniciais } \\
\text { na perspectiva da Educação Matemática Realística }\end{array}$ \\
\hline $\mathbf{( 2 0 2 1 )}$ & Ana Karina Cancian Baroni & $\begin{array}{l}\text { Educação Financeira no contexto da Educação } \\
\text { Matemática: possibilidades para a formação inicial do } \\
\text { professor }\end{array}$ \\
\hline
\end{tabular}

Fonte: Autores.

Vieira (2019) - ao defender que o currículo e a formação inicial do professor de Matemática devem ser modificados expõe os seguintes questionamentos:

Como os bacharéis e/ou licenciados em Matemática estão letrados financeiramente ao nível exigido para os propósitos da Estratégia Nacional de Educação Financeira (ENEF)? Quais as características relativas ao processo de formação inicial e atuação dos professores de Matemática, concernentes à Educação Financeira nos Municípios de Carangola MG, Dores do Rio Preto - ES e Espera Feliz - MG, podem ser identificadas? (Vieira, 2019, p. 24). 
Para responder a tais questionamentos, Vieira (2019) aplica um questionário aos professores, no qual a análise de dados foi feita com suporte do software CHIC (Classificação Hierárquica, Implicativa e Coesitiva), cujos resultados apontam para a percepção de que a Educação Financeira é confundida com a Matemática Financeira, que é abordada em sala de aula de maneira superficial, como por meio de conceitos direcionados à porcentagem e juros.

Ainda com relação ao comentário anterior, a Matemática Financeira diverge da proposta da ENEF, uma vez que seu intento é proporcionar ao aluno as orientações para a construção de um pensamento financeiro consciente. Além de indicar que o professor de matemática da Educação Básica não está preparado para trabalhar a Educação Financeira de forma efetiva com os discentes, o que torna evidente a necessidade de uma formação inicial adequada, assim como uma formação continuada, uma vez que a pesquisa aponta que poucas instituições do Ensino Superior ofertam a disciplina de Educação Financeira como formação inicial do futuro professor.

Em outra pesquisa, de Ferreira (2020), diante do propósito de criar e investigar um ambiente de aprendizagem a partir da elaboração de atividades e de uma Sequência Didática (SD) ancorada na Educação Matemática Realista (EMR), a autora buscou responder a seguinte questão:

Quais as contribuições que a sequência didática construída segundo os pressupostos da ERM pode auxiliar na compreensão dos conceitos de Educação Financeira Escolar com acadêmicos de um curso de Pedagogia? (Ferreira, 2020, p. 18).

Na pesquisa, Ferreira (2020) utiliza o diário de campo da pesquisadora, as observações das aulas, os relatórios e registros escritos das atividades realizadas pelos estudantes. A metodologia de análise dos dados foi definida de modo a considerar os procedimentos da Análise de Conteúdo, utilizando, para isso, da modalidade de análise temática, que ocorre em três fases: (1) pré-análise, (2) exploração do material e (3) tratamento dos resultados, os quais assinalam que a abordagem da EMR contribui de forma significativa para o desenvolvimento da Sequência Didática e às discussões quanto à interpretação de problemas, pensamento social e matemático.

Segundo a autora, essas discussões despertam nos acadêmicos o interesse, a curiosidade, a autonomia, a cooperação e a reflexão sobre as situações financeiras. Além disso, verifica-se, ainda, como o ensino da matemática a partir de contextos que envolvem questões financeiras e cotidianas, podem ser alcançados com a motivação e interesse dos estudantes.

Em sua tese, Baroni (2021) afirma que frente aos problemas sociais, por exemplo, como o endividamento familiar, a relação entre o consumo e o aproveitamento responsável de recursos naturais, mostra-se necessário e eficaz no ensino da Educação Financeira e sua implementação nos currículos da Educação Básica. Diante disso, a autora procura resolver o seguinte problema de pesquisa: "Quais as possibilidades da Educação Financeira no contexto da Educação Matemática, no que se refere à formação inicial de professores?” (Baroni, 2021, p. 43).

Baroni (2021) considera para a produção de dados, uma instituição pública federal por meio da pesquisa documental, entrevistas e discussões geradas em um ambiente virtual, no âmbito de um grupo de trabalho colaborativo, composta por membros formadores de professores com experiência em disciplinas voltadas à Educação Financeira. Os resultados encontrados pela autora consistiram nas possibilidades da Educação Financeira na formação inicial do professor de Matemática, como forma de problematizar a vida financeira e suas implicações sociais, além de estabelecer, por meio de uma abordagem dialógica, a reflexão sobre o assunto, assim, propondo uma visão contrária àquela que se reduz ao ensinar consumir.

É possível observar por meio dos trabalhos discutidos, no Quadro 2, que existe a necessidade de o futuro professor vivenciar em sala de aula questões que dizem respeito à Educação Financeira, não apenas sob a perspectiva da disciplina de 
Matemática, como, também, a partir da finalidade de uma compreensão sobre a vida financeira dos futuros jovens. Haja vista que, em sua totalidade, os estudos apontam para a falta de formação financeira específica.

\subsection{Formação continuada de professores}

Freire (1996) identifica que a formação docente deve ser contínua, profunda, dialógica e dialética. Nota-se, nas pesquisas analisadas, que esses intentos mostram-se fundamentais no processo de ensino e aprendizagem dos alunos, ainda mais envolvendo a aquisição do conhecimento financeiro.

Para Nóvoa (2002), o contínuo processo de aprendizagem é essencial ao concentrar-se em dois pilares: a própria pessoa e a escola, que representa o permanente crescimento profissional dos sujeitos sociais.

Vieira (2019) defende a formação continuada como parcela do desenvolvimento profissional ao longo da docência a qual possibilita avanços na prática pedagógica, tornando a atuação do professor significativa tanto em sala de aula quanto para a sociedade.

Em relação a mobilização de conhecimentos pedagógios e matemáticos envolvendo a Educação Financeira, foram econcontrados cinco dissertações, conforme apresentadas no Quadro 3:

Quadro 3 - Formação continuada de professores sobre a temática Educação Financeira nos anos iniciais do E.F.

\begin{tabular}{|l|l|l|}
$\begin{array}{l}\text { Ano } \\
\text { Publicação }\end{array}$ & Autor & Título \\
\hline $\mathbf{( 2 0 1 7 )}$ & Daniela Flores Teixeira & $\begin{array}{l}\text { Educação Financeira no Ensino Fundamental: conhecimentos } \\
\text { identificados em um grupo de professsores do quinto ano }\end{array}$ \\
\hline $\mathbf{( 2 0 1 7 )}$ & Anaelize dos Anjos Oliveira & $\begin{array}{l}\text { Educação Financeira nos anos iniciais do Ensino Fundamental: } \\
\text { como tem ocorrido na sala de aula? }\end{array}$ \\
\hline $\mathbf{( 2 0 1 7 )}$ & Laís Thalita Bezzera Santos & $\begin{array}{l}\text { Educação Financeira em livros didáticos de matemática dos } \\
\text { anos iniciais do ensino fundamental: quais as atividades } \\
\text { sugeridas nos livros dos alunos e as orientaçôes presentes nos } \\
\text { manuais dos professores? }\end{array}$ \\
\hline $\mathbf{( 2 0 1 8 )}$ & Arlam Dielcio Pontes Silva & $\begin{array}{l}\text { Atividades de Educação Financeira em livro didático de } \\
\text { matemática: } \text { como professores colocam em prática? }\end{array}$ \\
\hline $\mathbf{( 2 0 1 9 )}$ & Sílvia Helena da Silva Souza & $\begin{array}{l}\text { Educação Financeira: } \text { olhar sobre a prática do professor que } \\
\text { ensina matemática nos anos iniciais do ensino fundamental }\end{array}$ \\
\hline
\end{tabular}

Fonte: Autores.

Teixeira (2017, p. 32), por meio de uma entrevista semiestruturada, buscou responder à seguinte questão:

Que tipos de conhecimentos são identificados em professores do $5^{\circ}$ ano quanto à Educação Financeira quando estes descrevem suas práticas em aula e resolvem problemas relativos ao tema? Que características didáticas podem ser identificadas nessa mobilização?

A autora supracitada menciona que a pesquisa foi composta por meio da participação de cinco professoras em um estudo de caso, desenvolvido em três etapas (levantamento do perfil das docentes, identificação dos conhecimentos e resolução de situações sobre Educação Financeira). Como resultado, Teixeira (2017) constatou que o fato de as professoras entrevistadas terem formação em Pedagogia; não possuírem curso específico em matemática; ligarem os conteúdos de Educação Financeira ao Sistema Monetário; ou ainda, mostrarem interesse para a introdução de conteúdos ligados à Matemática, revelou a necessidade da criação de formações continuadas que abordem o tema Educação Financeira nas escolas de forma a oportunizar o desenvolvimento adequado do conhecimento pedagógico do professor. 
Oliveira (2017) observa 8 aulas e realiza entrevistas semiestruturadas, com uma supervisora e duas professoras, uma do $4^{\circ}$ ano e outra do $5^{\circ}$ ano de uma escola da rede privada da cidade do Recife. Na pesquisa, a autora buscou responder aos seguintes questionamentos:

Como está ocorrendo a inserção da temática Educação Financeira na escola privada? O que o professor compreende? Como é norteada a prática docente em turmas de $4^{\circ}$ e $5^{\circ}$ anos do Ensino Fundamental? Que tipos de atividades são propostas? Quais conteúdos matemáticos estão presentes nas atividades? (Oliveira, 2017, p. 17).

Oliveira (2017) encontrou como resultado que a inserção da temática no ambiente escolar ocorre a partir da compra de um programa de Educação Financeira fornecido pelo Grupo DSOP, de Educação Financeira, que consisti em livros didáticos e paradidáticos específicos os quais fornecem formações acerca da temática.

A autora mencionada ressalta que a discussão de temas que extrapolam o poupar e o consumo de bens supérfluos explicitam os entendimentos e a importância conferida à temática pelas docentes. Além disso, a pesquisadora identifica que as atividades desenvolvidas nas aulas de Educação Financeira envolvem tanto conteúdos matemáticos, quanto contextos nos quais podem ser discutidos temas relacionados a outras disciplinas.

Resultado este responsável por evidenciar que as questões relacionadas à Educação Financeira podem ser discutidas a partir de outras disciplinas, enriquecendo as discussões. A partir desses resultados descritos, defende-se que a Educação Financeira tem como objetivo mobilizar ambientes de reflexão para que os alunos possam tomar decisões de forma crítica.

No estudo desenvolvido por Santos (2017, p. 17), verifica-se a busca por responder a seguinte questão de pesquisa:

Quais são as atividades presentes nos livros dos alunos que têm potencial para trabalhar a Educação Financeira, bem como, quais são as orientações presentes nos manuais de professores de livros didáticos dos anos iniciais do Ensino Fundamental sobre o desenvolvimento do trabalho com Educação Financeira?

Para tanto, o pesquisador utiliza-se da técnica dos ambientes de aprendizagem de Skovsmose (2000), das categorias das temáticas elencadas a partir das atividades propostas nos livros didáticos, e, também, das orientações presentes nos manuais dos professores. Nesta investigação, o autor buscou analisar todos os livros didáticos de Matemática dos anos iniciais do Ensino Fundamental, aprovados pelo Programa Nacional do Livro didático - PNLD (2016), que orientam o desenvolvimento de um trabalho com a Educação Financeira, dessa forma, totalizando 32 livros para análise.

Os resultados encontrados pelo autor apontaram para a existência de 48 atividades sobre Educação Financeira, sendo que desse total, apenas 26 exercícios permitiram a identificação do tema Educação Financeira.

Santos (2017), a partir do manual, destacou que a maioria das atividades estavam dissociadas de conteúdos matemáticos, o que indica a possibilidade de trabalho com a Educação Financeira a partir de outras disciplinas, logo, não sendo, portanto, tal temática exclusiva da Matemática. Nessa pesquisa, defende-se, por meio dos resultados, que a discussão sobre a Educação Financeira e, consequentemente, as atividades propostas em torno do tema, ocorrem de forma mais sistematizada nos livros didáticos (LD) de Matemática dos anos iniciais, e não de modo pontual como foi encontrada.

Silva (2018) à luz da Educação Matemática Crítica (Skovsmose, 2014) e por meio de duas atividades - uma com maior potencial para o trabalho com a temática e para criar cenários para investigação e outra com menor potencial, a fim de responder a seguinte questão:

Como um grupo de 8 professores do $2^{\circ}$ ano do Ensino Fundamental, da rede municipal de Educação de GaranhunsPE, colocam em prática atividades de Educação Financeira propostas em livros didáticos? (Silva, 2018, p. 21). 
Após a aplicação da entrevista, a pesquisadora solicitou a quatro professores que elaborassem um plano de aula a partir da atividade com maior potencial para criar cenários de investigação, sendo que dois receberam o manual do livro, e outros dois não. Desse modo, na atividade, os demais elaboraram o plano de aula a partir da atividade com menor potencial (Silva, 2018).

A partir dos resultados, a autora conclui que a escassez de conhecimento na área de Educação Financeira por parte dos professores, participantes da pesquisa, faz-se notória, uma vez que estes não costumam utilizar o livro didático em suas práticas docentes. Porém, Silva (2018) conseguiu identificar, nos planos de aula elaborados, abordagens voltadas à criação de cenários os quais poderiam ser utilizados para investigação. Portanto, concluindo que existe possibilidade de criação de cenários para investigação, ainda que os professores tenham pouco conhecimento a respeito do tema.

Souza (2019) opta pela pesquisa ação, cujo procedimento é interpretado como SD (Sequência Didática), que caracteriza um modelo sistematizador do processo assistemático de Educação Financeira que já era desenvolvido pela professora antes da formação continuada. Para realização da pesquisa, Souza (2019, p. 16) utilizou os seguintes questionamentos:

Já que os alunos estão inseridos em situações de compra e venda de forma cotidiana, isso justificaria a abordagem da Educação Financeira nos anos iniciais do Ensino Fundamental? O professor trabalha a Educação Financeira no $3^{\circ}$ ano? Se trabalha. Como o faz? Se não, como poderia trabalhar essa temática em sala de aula?

O uso de tal método concilia os resultados da SD com o trabalho que a professora estava executando, considerando dois momentos: (i) a formação continuada, por meio do projeto "Educação Financeira nos anos iniciais do Ensino Fundamental" - que aconteceria na escola lócus - e a colaboração da professora pesquisadora para a elaboração e execução da Sequência Didática (Souza, 2019).

Souza (2019) obteve como resultados a conclusão de que a experiência da professora investigada mostrou que o professor responsável por ensinar a disciplina de Matemática já trabalhava a Educação Financeira. Porém, nesse caso, identificou-se que para a prática se tornar mais significativa aos alunos seria necessário que o professor passasse por um processo de letramento, isto é, aprendendo a estudar sobre o tema, investigando a própria prática, no sentido de promover a reflexão na ação.

Em relação às pesquisas discutidas, nota-se que os autores ao discutirem a relação da Educação Financeira com os conteúdos matemáticos e outras disciplinas, por exemplo, como a criação de cenários para investigação, apontam para a necessidade do contínuo letramento financeiro de professores de Matemática, que possam atuar de modo sistemático e profícuo na Educação Básica brasileira.

\section{Considerações Finais}

Este artigo buscou apresentar evidências empíricas da utilização de métodos que auxiliam no processo da Educação Financeira por meio da formação inicial e continuada de professores do Ensino Fundamental dos anos iniciais. Posto isto, a revisão bibliográfica sistematizada mostrou a ocorrência de estudos, ainda, escassos na área.

Ao considerar as propostas dos pesquisadores brasileiros (em relação às práticas de Educação Financeira com foco na formação de professores que atuam nos anos iniciais do Ensino Fundamental), no período de 2016 a 2021, constatou-se a produção de oito trabalhos. Por meio dos quais observou-se que o professor da disciplina de Matemática dos anos iniciais não está preparado para atuar com a temática Educação Financeira de forma efetiva, devido à má formação inicial, ou mesmo, pela ausência de uma formação continuada. 
Nesse sentido, por fim, torna-se evidente a necessidade de investimento em letramento financeiro aos professores, para que haja o aperfeiçoamento da prática docente, reflexiva e de interdisciplinaridade na Educação Financeira.

Espera-se, a partir dos trabalhos levantados para análise no presente artigo, que a temática Educação Financeira seja abordada com maior foco e preocupação considerando a realidade financeira particular de cada família dos alunos/estudantes. E, ainda, que futuros trabalhos acadêmicos em torno do tema proponham planejamentos, os quais possam auxiliar tanto os professores em formação quanto aqueles que já atuam na Educação Básica, de modo que as atividades de Matemática sejam adaptadas aos conteúdos informativos sobre Educação Financeira.

\section{Agradecimentos}

Em especial, à revista Research, Society and Development, pela atenção aos trabalhos acadêmicos publicados.

E, aos pesquisadores que se debruçam sobre o tema, que nos permitiram apoio teórico às citações deste artigo.

\section{Referências}

Baroni, A. K. C. (2021). Educação Financeira no contexto da Educação Matemática: possibilidades para a formação inicial do professor. [Tese de doutorado em Educação Matemática, Universidade Estadual Júlio de Mesquita Filho, Rio Claro]. f. 253.

Brasil/ENEF. (2010). Estratégia Nacional de Educação Financeira. Plano Diretor da ENEF: Anexos. Decreto $\mathrm{n}^{\circ} 7397$ publicado em 22/12/2010. http://www.vidaedinheiro.gov.br/legislação.

Brasil. (2017). Secretaria de Educação Básica. Proposta da Base Nacional Comum Curricular. Resolução CNE/CP nº 2 publicada em 22/122017. http://basenacionalcomum.mec.gov.br/.

Banco Central do Brasil. (2016). Brasil: implementando a Estratégia Nacional de Educação Financeira. Publicado em 28/04/2016.

https://www.bcb.gov.br/pre/pef/PORT/enef.asp?frame=1.

Bonneau, Pierre. (1980). Mathématiques financières. Dunod.

Chevallar, D. Y. (2007). Un concept en émergence :la dialectique des médias et des milleux. In: G. Gueudet \& Y. Matheron (Eds). Actes du séminaire national de didactique des mathématiques, année 2007, ARDM et IREM de Paris. 344-366. http://yves.chevallard.free.fr/spip/spip/article.php3?id_article=147.

Chevallard, Y. (2009). La notion de PER: problèmes et avancées. UMRADEF. Toulouse, Canadá. 29. http://yves.chevallard.free.fr/spip/spip/IMG/pdf/La_notion_de_PER__problemes_et_avancees.pdf .

D’Aquino, C.; \& Maldonado, M. T. (2012). Educar para consumo: como lidar com os desejos de crianças e adolescentes. Papirus 7 Mares.

D’Ambrosio, U. (2002). Que matemática deve ser aprendida nas escolas hoje? Teleconferência no Programa PEC - Formação Universitária, patrocinada pela Secretaria de Educação do Estado de São Paulo. https://sites.google.com/site/etnomath/5.

Ferreira, S. M. (2020). Construção de conceitos de educação Financeira escolar na formação inicial de professores dos anos iniciais na perspectiva da educação matemática realística. [Tese de doutorado em Ensino de Ciências e Matemática, Universidade Franciscana - UFN]. f. 210.

Freire, P. (1996). Pedagogia da autonomia: saberes necessários à prática educativa. (34a ed.), Paz e Terra.

Infomoney. (2021). Como ensinar o que não se aprendeu: os desafios da Educação Financeira no Brasil. https://www.infomoney.com.br/colunistas/convidados/como-ensinar-o-que-nao-se-aprendeu-os-desafios-da-educacao-financeira-no-brasil/.

Keele, S. (2007). Guidelines for performing systematic literature reviews in software engineering. Technical report, EBSE Technical Report EBSE. https://www.elsevier.com/_data/promis_misc/525444systematicreviewsguide.pdf.

Nóvoa, A. (1992). Os professores e sua formação. Dom Quixote, 27.

Nóvoa, A. (2002). Formação de professores e trabalho pedagógico. Educa, 46.

OECD`s Financial Education Project. (2009). Assessoria de Comunicação Social. Resolução CNJ nº 85/2009 publicada em 17/09/2009.

Oliveira, A. dos A. (2017). Educação financeira nos anos iniciais do ensino fundamental: como tem ocorrido na sala de aula? [Dissertação de mestrado em Educação Matemática e Tecnológica, Universidade Federal de Pernambuco]. f.161.

Olivieri, M. de F. A. (2013). Educação Financeira. Revista ENIAC Pesquisa, 2(1), 43-51. https://ojs.eniac.com.br/index.php/EniacPesquisa/article/view/108. DOI:http://dx.doi.org/10.22567/rep.v2i1.108.

Sampaio, R. F, \& Mancini, M. C. (2007). Estudos de Revisão Sistemática: um guia para síntese criteriosa da evidência científica. Revista Brasileira de Fisioterapia. $\quad$ 83-89. https://www.scielo.br/j/rbfis/a/79nG9Vk3syHhnSgY7VsB6jG/?lang=pt\&format=pdf. https://doi.org/10.1590/S141335552007000100013 . 
Research, Society and Development, v. 10, n. 13, e194101320926, 2021

(CC BY 4.0) | ISSN 2525-3409 | DOI: http://dx.doi.org/10.33448/rsd-v10i13.20926

Santos, L. T., \& Bezzera, dos S. (2017). Educação Financeira em livros didáticos de matemática dos anos iniciais do ensino fundamental: quais as atividades sugeridas nos livros dos alunos e as orientaçães presentes nos manuais dos professores? [Dissertação de mestrado em Educação Matemática e Tecnológica, Universidade Federal de Pernambuco]. f. 205.

Silva, A., \& Dielcio, P. (2018). Atividades de educação financeira em livro didático de matemática: como professores colocam em prática? [Dissertação de mestrado do Programa de Pós-graduação em Educação Matemática e Tecnológica, Universidade Federal de Pernambuco, C], f. 200.

Souza, S. H. da S. (2019). Educação Financeira: olhar sobre a prática do professor que ensina matemática nos anos iniciais do ensino fundamental. [Dissertação de mestrado do Programa de Pós-Graduação em Docência em Educação em Ciências e Matemática, Instituto de Educação Matemática e Científica, Universidade Federal do Pará, Belém]. f. 142.

Tardif, M. (2002). Saberes docentes e formação profissional. Vozes, 1-111.

Tardif, M. (2012). Saberes docentes e formação profissional. (14a ed.), Vozes.

Teixeira, D. F. (2017). Educação Financeira no ensino fundamental: Conhecimentos identificados em um grupo de professores de $5^{\circ}$ ano. [Dissertação de Mestrado em Educação Matemática, Pontifícia Universidade Católica de São Paulo]. f.118.

Vieira, T. V. (2019). Um estudo sobre a atuação e a formação dos professores de Matemática em relação a Educação Financeira nos municípios Carangola $M G$, Dores do Rio Preto - ES e Espera Feliz-MG. [Dissertação de Mestrado em Ensino, Universidade Federal Fluminense]. f.112. 